\title{
Predictors of Health-Related Quality of Life in Stroke Survivors After Inpatient rehabilitation
}

\author{
Nataša Rančić ( $\nabla$ drrancicnatasa@gmail.com ) \\ University of Niš, Medical Faculty \\ Milan Mandić \\ Clinic of Physical Medicine and Rehabilitation \\ Dragan Bogdanović \\ Institute of Public Health \\ Biljana Kocić \\ University of Niš, Medical Faculty \\ Konstanca Lazarević \\ Institute of Public Health
}

\section{Research article}

Keywords: stroke, survivors, health-related quality of life, inpatient rehabilitation

Posted Date: December 13th, 2019

DOI: https://doi.org/10.21203/rs.2.18990/v1

License: (c) (i) This work is licensed under a Creative Commons Attribution 4.0 International License.

Read Full License 


\section{Abstract}

Background. Disordered and decreased quality of life is the most important consequence of stroke for stroke survivors. The aim of the study was to determine the predictors of the health-related quality of life (HRQOL) in stroke survivors six months after discharge from inpatient rehabilitation.

Methods. We conducted prospective cohort study which involved 136 (48.5\% males and $51.5 \%$ females) survivors. We examined seven potential predictors of HRQOL: age, sex, stroke type, stroke side, functional status (Barthel Index-BI and modified Rankin Scale-mRS), cognition (Mini-Mental State Examination; MMSE) and stroke severity (National Institutes of Health Stroke Scale; NIHSS). HRQOL was assessed by Stroke Impact Scale (SIS) 3.0. Using Pearson's correlation and multiple logistic regression analysis we described the relationships between mRS, NIHSS, BI, MMSE and HRQOL.

Results. Baseline mRS and NIHSS scores negatively correlated with seven SIS domains except with strength. Baseline BI scores positively correlated with seven SIS domains except mobility and baseline MMSE scores positive correlated with memory, ADL, hand function and participation role and negatively correlated with emotion, communication and mobility domains. Decrease of both mRS and NIHSS scores during the observed period positively correlated with increase of all SIS domains. Ischaemic stroke positively correlated with emotion and communication and stroke in brainstem negatively correlated with communication domain. Memory domain positively correlated with female sex and with stroke in the right hemisphere. Age wasn't significantly associated with any SIS domain.

Conclusion. We conclude that major factors in predicting the improvement of strength, physical functioning, mobility, hand function, $A D L$ and participation role were increase of $\mathrm{BI}$ and decrease of $\mathrm{mRS}$ and NIHSS scores. Female sex, stroke in right hemisphere and increase of $\mathrm{BI}$ and MMSE scores predicted better memory. Baseline mRS and NIHSS scores were predictors for improvement of hand function and increase of $\mathrm{mRS}$ predicted decrease of hand function and participation role.

Key words: stroke, survivors, health-related quality of life, inpatient rehabilitation

\section{Background}

Stroke is one of most devastating neurological diseases and one of the leading causes of significant disability [1]. The World Health Organization (WHO) defines stroke as a focal or global neurological impairment of sudden onset, lasting more than 24 hours or leading to death of presumed vascular origin [2].

Stroke is the second cause of death worldwide and $87 \%$ of recorded deaths occur in low- and middleincome countries [3]. Stroke mortality declined in high-income countries like the United States of America (USA) $[4,5]$ and today stroke is on the fourth place as cause of death in the USA $[6,7]$. 
More than one third, out of 15 million people who suffered from stroke every year worldwide, will die and about $30 \%$ of stroke survivors will be significantly disabled $[8,9]$. Both physical and mental disabilities are common after stroke but the cognitive impairments are very often unrecognized despite of their high prevalence which ranged from $20 \%$ to $80 \%$ [10]. While physical disabilities tend to improve during the time cognitive impairments are progressively worsening $[10,11]$.

Impaired and decreased quality of life is the most important consequence of stroke for stroke survivors (12). Health-Related Quality of Life [HRQOL] is a broad, multidimensional concept referring to those aspects of people's lives that reasonably relate to their health [13].

Age, sex, socioeconomic status, stroke severity, motor impairments and depression are some of factors associated with poor HRQOL in stroke survivors [14-16]. Static and dynamic balance ability, cognition function, motor function, neurological deficit, stroke side and stroke type may influence on the total HRQOL or on some domains such as strength, memory, hand function, emotions, activity of daily living (ADL) $[17,18]$.

Assessment of the HRQOL is important measure of stroke treatment and rehabilitation efficacy [19]. It is assessed that only $10 \%$ of survivors make a full recovery, about $25 \%$ of all survivors recover with minor impairments and about $40 \%$ all survivors continue to live with moderate disabilities, while 15 to $30 \%$ live with severe disabilities and are full dependent [20]. About $25 \%$ of survivors need additional treatment and rehabilitation in specialized institutions [21].

The aim of the study was to determine the potential predictors of the HRQOL in stroke survivors six months after discharge from inpatient rehabilitation.

\section{Methods}

We carried out prospective cohort study which involved at first 216 survivors. Out of all of them 11 dropped out, 9 died, 60 didn't go to inpatient rehabilitation. Finally, cohort included 136 stroke survivors aged 40-79 years of age from the teritory of the Southeastern Serbia. All stroke survivors had inpatient rehabilitation in tertiary health institutions in the period of 30 days at Clinic for Physical Medicine and Rehabilitation, of the Clinical Centre Niš, Serbia, followed by prolonged rehabilitation in spa conditions for 30 days under medical control.

In Serbia, most stroke survivors with functional deficit after acute treatment in intensive care units (ICU) are offered 14 to 30 days of inpatient rehabilitation. Rehabilitation begins in the ICU when patient state is stable and after discharged majority of survivors from the territory of the Southeastern Serbia continuate rehabilitation at the Clinic for Physical Medicine and Rehabilitation, of the Clinical Centre Niš.

The inclusion criteria were: the first-ever stroke, the age from 40 to 79 years, possible communication with all participants and the written consent of all participants to participate in the study. 
The excluding criteria were: previously experienced stroke, pre-stroke cognitive impairments, insufficient cooperation of patients, psycho-organic syndrome, aphasia, transistent ischaemic attack (TIA), new stroke within 90 days of the first stroke, complications after stroke, the death of the participant.

The study took place from 1 April 2012 to 1 April 2016. The first assessments (baseline) were done at the admission to the Clinic for Rehabilitation and Physical Medicine and included functional status, cognitive function, neurological status and HRQOL. Data about survivors and stroke-related clinical characteristics were collected too. The second assessments were done six months after discharged from rehabilitation.

\section{Functional status}

Functional status was assessed with Barthel Index (BI) and by the modified Rankin scale (mRS).

BI measures the patient's performance in 10 activities of Activities of Daily Living (ADL), a group of questions that is related to self-care (feeding, grooming, bathing, dressing, bowel and bladder care, and toilet use) and a group related to mobility (ambulation, transfers, and stair climbing). The maximal score for $\mathrm{BI}$ is 100 indicating that the patient is fully independent in physical functioning. The lowest score is 0 , representing a totally dependent bedridden state [22].

The modified Rankin scale (mRS) [23] is regarded as a global stroke scale scoring patients' daily functioning from 0 (no symptoms) to 5 (severe disability, bedridden, in need of constant care) or 6 (death). Higher points indicate a severe disability.

\section{Cognitive function assessment}

Cognitive function was assessed by the Mini Mental State Examination (MMSE). MMSE is considered as a useful measure for the assessment of cognitive decline in stroke survivors [24]. This scale examines orientation, memorizing, attention and calculation, delayed memory, speaking, reading, writing and drawing. The maximum score is 30 , and a score of less than 24 points indicates the cognitive impairments.

\section{The National Institutes of Health Stroke Scale}

Neurological impairments were assessed by the National Institutes of Health Stroke Scale (NIHSS). This scale is consisted of 15 items for evaluation of size and location of stroke in the acute phase and as measure of neurological handicap. Total scores range from 0 to 42 and higher scores indicate greater stroke severity [25].

\section{The Stroke Impact Scale}


The Stroke Impact Scale (SIS) is a stroke-specific and self-reported questionnaire which consists of 59 items measuring eight domains (strength, hand function, activities of daily living/instrumental activities of daily living, mobility, communication, emotion, memory and thinking, and participation role). Each domain of SIS has a range of $0-100$ and higher scores indicated better HRQOL [26].

\section{The statistical analysis}

All the calculations were done into the SPSS software package version 18.0 and S-PLAS programme, version 2000. Student's t-test was used to compare numerical differences of normal distribution and the Mann-Whitney $\mathrm{U}$ test was used to compare two values when there were not normally distributed. Chi squared test and Fisher's test of exact probability were used too.

The Pearson's correlation analysis was calculated for the association among the continuous variables (age, BI, mRS, MMSE, NIHSS). Effects of independent variables (for continuous variables) on the dependent variable (SIS domains) were assessed by multivariate stepwise linear regression analysis. Regression coefficient (B) and the $95 \%$ confidence intervals $(95 \% \mathrm{Cl}$ for B) were calculated too. Statistical significance was accepted when the corresponding $p$-values was less than $0.05(p<0.05)$.

\section{Results}

The total of 136 ( $48.5 \%$ males and $51.5 \%$ females) stroke survivors participated in the study. The average age of participants was $63.72 \pm 8.73$.

Table 1. Basic demographic and clinical characteristics of the study population 
Table 1

Basic demographic and clinical characteristics of the study

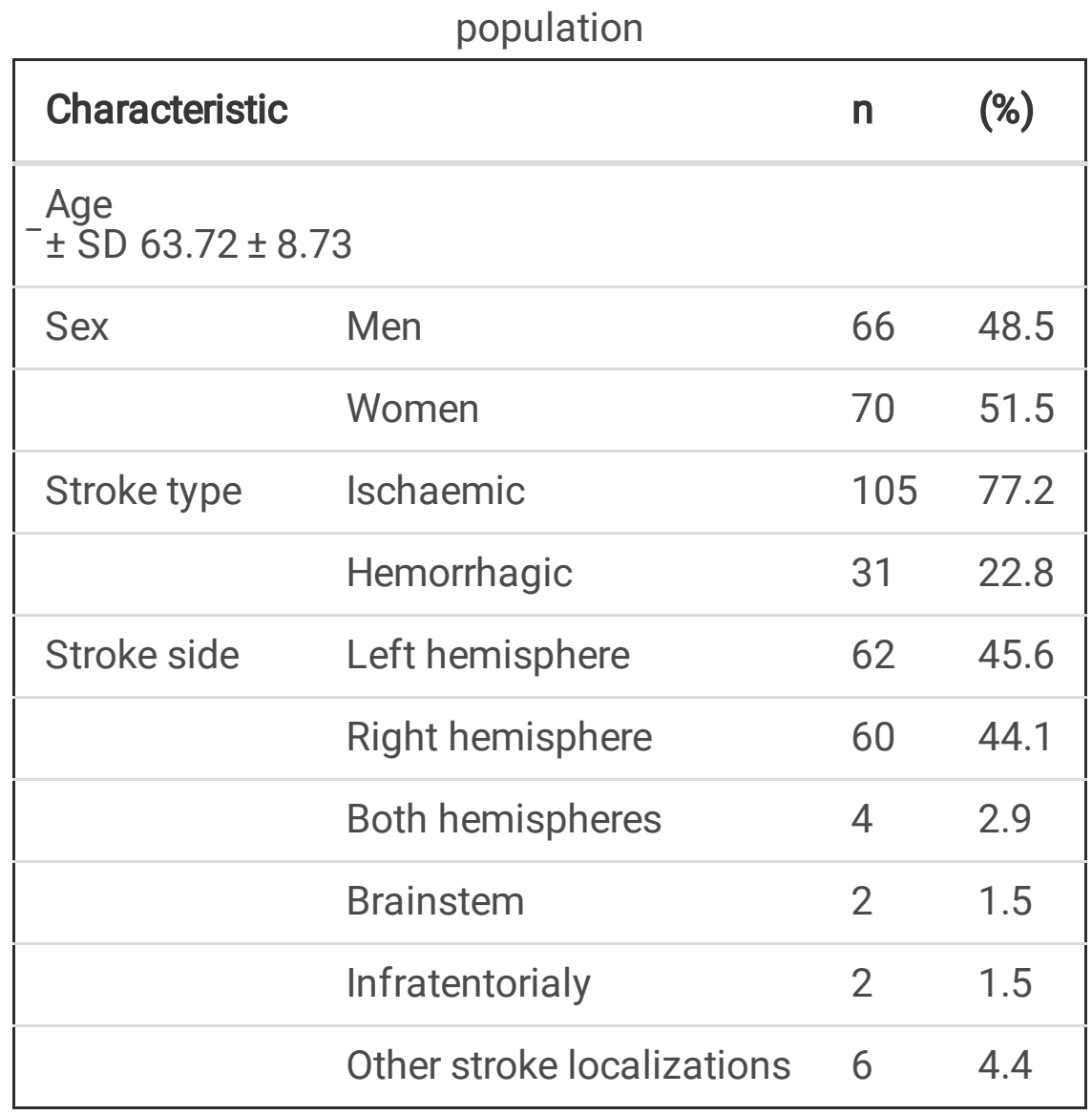

There were more women than men 51.5\%:48.5\% and there were more survivors with ischaemic stroke (77.2\%:22.8\%) than with hemorrhage. Determined differences were not significant (Chi square, Fisher's test: $p>0.05)$.

The most common localization of stroke was the left hemisphere (45.6\%), followed by the right hemisphere (44.1\%). Stroke localizations in both hemispheres accounted for $2.9 \%$, stroke in brainstem represented $1.5 \%$ and infratentorialy localized stroke accounted for $1.5 \%$. Other stroke localizations represented $4.4 \%$ of all strokes.

Table 2 presents the average scores of SIS domains at admission to inpatient rehabilitation and six months after discharge 
Table 2

The average scores of SIS domains at admission to inpatient rehabilitation and six months after discharge

\begin{tabular}{|lll|}
\hline & Average scores & Average scores \\
\hline SIS domains & at admission & six months after inpatient rehabilitation \\
\hline Strength & $24.82 \pm 21.46$ & $69.67 \pm 27.43$ \\
\hline Memory & $49.72 \pm 28.18$ & $80.88 \pm 23.16$ \\
\hline Emotion & $49.39 \pm 12.51$ & $58.82 \pm 9.83$ \\
\hline Communication & $65.49 \pm 28.77$ & $91.02 \pm 18.74$ \\
\hline ADL & $9.34 \pm 14.77$ & $60.82 \pm 31.88$ \\
\hline Mobility & $10.81 \pm 18.64$ & $69.96 \pm 28.13$ \\
\hline Hand function & $2.87 \pm 13.75$ & $45.51 \pm 41.60$ \\
\hline Participation role & $2.98 \pm 9.60$ & $38.44 \pm 34.11$ \\
\hline
\end{tabular}

Baseline average scores of hand function, mobility, strength, ADL and participation role domains were the most decreased at the admission to inpatient rehabilitation. The highest average scores were found in communication, memory and emotion domains. Significant increase of all eight domains was determined six months after discharge from inpatient rehabilitation.

Table 3 presents Pearson's correlation coefficients of the examined possible predictors and the scores of SIS domains. 
Table 3

Relationships between the potential predictors of HRQOL and the SIS domains in stroke survivors: results of correlation analysis

\begin{tabular}{|c|c|c|c|c|c|}
\hline \multicolumn{2}{|l|}{ Variables } & \multirow[t]{2}{*}{ B constant } & \multicolumn{2}{|l|}{$95 \% \mathrm{Cl}$} & \multirow[t]{2}{*}{$\mathbf{p}$} \\
\hline Dependent variables & Independent Variables & & Lower limit & Upper limit & \\
\hline \multirow[t]{3}{*}{ Strength } & Constant & -12.995 & -22.493 & -3.497 & 0.008 \\
\hline & $\mathrm{BI}$ & 0.603 & 0.491 & 0.716 & $<0.001$ \\
\hline & NIHSS & -1.587 & -2.254 & -0.921 & $<0.001$ \\
\hline \multirow[t]{6}{*}{ Memory } & Constant & -45.249 & -65.580 & -24.919 & $<0.001$ \\
\hline & Female gender & 6.025 & 1.659 & 10.391 & 0.007 \\
\hline & Left hemisfere & 11.456 & 6.833 & 16.078 & $<0.001$ \\
\hline & $\mathrm{mRS}$ & -4.494 & -7.236 & -1.752 & 0.001 \\
\hline & $\mathrm{BI}$ & 0.208 & 0.094 & 0.321 & $<0.001$ \\
\hline & MMSE & 1.979 & 1.139 & 2.818 & $<0.001$ \\
\hline \multirow[t]{2}{*}{ Emotion } & Constant & 1.024 & -2.263 & 4.311 & 0.540 \\
\hline & $\mathrm{BI}$ & 0.149 & 0.095 & 0.203 & $<0.001$ \\
\hline \multirow[t]{4}{*}{ Communication } & Constant & 4.772 & -5.886 & 15.431 & 0.378 \\
\hline & $\mathrm{BI}$ & -0.259 & -0.386 & -0.133 & $<0.001$ \\
\hline & MMSE & 0.741 & 0.088 & 1.394 & 0,026 \\
\hline & NIHSS & 3.081 & 1.829 & 4.332 & $<0.001$ \\
\hline \multirow[t]{4}{*}{ ADL } & Constant & 15.759 & -19.279 & 50.798 & 0.376 \\
\hline & $\mathrm{mRS}$ & -10.097 & -13.290 & -6.905 & $<0.001$ \\
\hline & $\mathrm{BI}$ & 0.531 & 0.325 & 0.738 & $<0.001$ \\
\hline & MMSE & 0.396 & 0.004 & 0.787 & 0.047 \\
\hline \multirow[t]{5}{*}{ Mobility } & Constant & -115.064 & -151.964 & -78.164 & $<0.001$ \\
\hline & $\mathrm{mRS}$ & 11.067 & 4.791 & 17.343 & 0.001 \\
\hline & $\mathrm{BI}$ & 0.985 & 0.818 & 1.153 & $<0.001$ \\
\hline & MMSE & 1.172 & 0.413 & 1.931 & 0.003 \\
\hline & NIHSS & -1.541 & -2.188 & -0.894 & $<0.001$ \\
\hline
\end{tabular}




\begin{tabular}{|c|c|c|c|c|c|}
\hline \multicolumn{2}{|l|}{ Variables } & \multirow[t]{2}{*}{ B constant } & \multicolumn{2}{|l|}{$95 \% \mathrm{Cl}$} & \multirow[t]{2}{*}{$\mathbf{p}$} \\
\hline Dependent variables & Independent Variables & & Lower limit & Upper limit & \\
\hline \multirow[t]{3}{*}{ Hand function } & Constant & 89.459 & 56.541 & 122.378 & $<0.001$ \\
\hline & $\mathrm{mRS}$ & -16.381 & -24.330 & -8.431 & $<0.001$ \\
\hline & NIHSS & -4.245 & -5.988 & -2.502 & $<0.001$ \\
\hline \multirow[t]{3}{*}{ Participation Role } & Constant & 110.731 & 80.309 & 141.152 & $<0.001$ \\
\hline & $\mathrm{mRS}$ & -29.573 & -35.012 & -24.133 & $<0.001$ \\
\hline & MMSE & 0.808 & 0.292 & 1.324 & 0.002 \\
\hline * $P<0.05 ;+P<0.01$ & & & & & \\
\hline
\end{tabular}

Correlation between examined predictors (age, sex, stroke side, stroke type, mRS, BI, MMSE and NIHSS) with each of the SIS domains is shown in Table 3.

Baseline mRS was negatively correlated with seven SIS domains except with strength. Similar findings were observed for NIHSS scores. Baseline BI scores positively correlated with seven SIS domains except mobility and baseline MMSE scores significantly positive correlated with memory, ADL, hand function and participation role and negatively correlated with emotion, communication and mobility domains.

Six months after discharge, decreased of both mRS and NIHSS scores were significantly correlated with increase of all SIS domains. Significantly positive correlation was determined between memory domain and female sex and with stroke in right hemisphere. Memory domain significantly positive correlated with decrease of mRS and NIHSS scores during the study and negatively correlated with stroke in left hemisphere. There was a significant positive correlation between memory domain and increase of MMSE scores.

Emotion domain significantly positive correlated with stroke type, infratentorialy stroke, increase of $\mathrm{BI}$ and MMSE scores and significant decrease of mRS during the study.

Significantly positive correlation was found between communication and stroke type and increase of BI and MMSE scores and with significant decrease of NIHHS scores. Communication domain was significantly negative correlated with stroke in brainstem.

A significantly positive correlation was determined between ADL and mobility domain, hand function, participation role with decrease of $\mathrm{mRS}$ and NIHSS scores during the study. Increase of $\mathrm{BI}$ and MMSE scores significantly positive correlated with ADL and mobility and decrease of mRS and increase of BI scores significantly positive correlated with hand function. There was a significant positive correlation between hand function and stroke in brainstem. Increase of mRSand NIHHS significant ly negative correlated with participation role. 
Table 4 presents relationships between the possible predictors and the SIS domains of stroke survivors six months after discharge from rehabilitation 
Table 4

Factors affecting the SIS domains of HRQOL: results of multivariate logistic regression analysis

\section{Variables}

\section{Dependent variables Independent Variables}

\begin{tabular}{|c|c|c|c|c|c|}
\hline \multirow[t]{3}{*}{ Strength } & Constant & -12.995 & -22.493 & -3.497 & 0.008 \\
\hline & $\mathrm{BI}$ & 0.603 & 0.491 & 0.716 & $<0.001$ \\
\hline & NIHSS & -1.587 & -2.254 & -0.921 & $<0.001$ \\
\hline \multirow[t]{6}{*}{ Memory } & Constant & -45.249 & -65.580 & -24.919 & $<0.001$ \\
\hline & Female sex & 6.025 & 1.659 & 10.391 & 0.007 \\
\hline & Right hemisfere & 11.456 & 6.833 & 16.078 & $<0.001$ \\
\hline & $\mathrm{mRS}$ & -4.494 & -7.236 & -1.752 & 0.001 \\
\hline & $\mathrm{BI}$ & 0.208 & 0.094 & 0.321 & $<0.001$ \\
\hline & MMSE & 1.979 & 1.139 & 2.818 & $<0.001$ \\
\hline \multirow[t]{2}{*}{ Emotion } & Constant & 1.024 & -2.263 & 4.311 & 0.540 \\
\hline & $\mathrm{BI}$ & 0.149 & 0.095 & 0.203 & $<0.001$ \\
\hline \multirow[t]{4}{*}{ Communication } & Constant & 4.772 & -5.886 & 15.431 & 0.378 \\
\hline & $\mathrm{BI}$ & -0.259 & -0.386 & -0.133 & $<0.001$ \\
\hline & MMSE & 0.741 & 0.088 & 1.394 & 0,026 \\
\hline & NIHSS & 3.081 & 1.829 & 4.332 & $<0.001$ \\
\hline \multirow[t]{4}{*}{ ADL } & Constant & 15.759 & -19.279 & 50.798 & 0.376 \\
\hline & $\mathrm{mRS}$ & -10.097 & -13.290 & -6.905 & $<0.001$ \\
\hline & $\mathrm{BI}$ & 0.531 & 0.325 & 0.738 & $<0.001$ \\
\hline & MMSE & 0.396 & 0.004 & 0.787 & 0.047 \\
\hline \multirow[t]{5}{*}{ Mobility } & Constant & -115.064 & -151.964 & -78.164 & $<0.001$ \\
\hline & $\mathrm{mRS}$ & 11.067 & 4.791 & 17.343 & 0.001 \\
\hline & $\mathrm{BI}$ & 0.985 & 0.818 & 1.153 & $<0.001$ \\
\hline & MMSE & 1.172 & 0.413 & 1.931 & 0.003 \\
\hline & NIHSS & -1.541 & -2.188 & -0.894 & $<0.001$ \\
\hline Hand function & Constant & 89.459 & 56.541 & 122.378 & $<0.001$ \\
\hline
\end{tabular}




\begin{tabular}{|llllll|}
\hline Variables & & B constant & $95 \% \mathrm{Cl}$ & \multicolumn{2}{c|}{ P } \\
\cline { 1 - 3 } Dependent variables & Independent Variables & & Lower limit & Upper limit & \\
\cline { 5 - 6 } & mRS & -16.381 & -24.330 & -8.431 & $<0.001$ \\
\hline PlHSS & -4.245 & -5.988 & -2.502 & $<0.001$ \\
\hline Participation Role & Constant & 110.731 & 80.309 & 141.152 & $<0.001$ \\
\hline & mRS & -29.573 & -35.012 & -24.133 & $<0.001$ \\
\hline & MMSE & 0.808 & 0.292 & 1.324 & 0.002 \\
\hline
\end{tabular}

Major factors in predicting the improvement of strength domain were $\mathrm{BI}$ and $\mathrm{NIHSS}$ scores. Increase of $\mathrm{BI}$ score (95\% Cl: 0.491 to $0.716 ; p<0.001)$ was associated with significant increase of strength and increase of NIHSS score was associated with significant decrease of strength domain ( $95 \% \mathrm{Cl}:-2.254$ to $-0.921 ; p<0.001)$.

Factors associated with improvement of memory domain were: female sex, stroke in right hemisphere, increase of BI scores $(95 \% \mathrm{Cl}: 0.094$ to $0.321 ; \mathrm{p}<0.001)$. The increase of memory domain during the study was significantly higher in women than in men (95\% Cl: 1.659 to $10.391 ; p=0.007)$. Increase of memory domain was significantly higher if stroke was in right hemisphere ( $95 \% \mathrm{Cl}: 6.833$ to $16.078 ; \mathrm{p}<$ $0.001)$.

Increase of $\mathrm{BI}(95 \% \mathrm{Cl}: 0.095$ to $0.203 ; \mathrm{p}<0.001)$ during the study was significantly associated with increase of emotion domain.

The most important factors associated with communication domain were: baseline $\mathrm{BI}$ ( $95 \% \mathrm{Cl}:-0.386$ to $-0,133 ; p<0.001)$ and NIHSS scores (95\% Cl: 1.829 to 4.332; $p<0.001)$ and increase of MMSE $(95 \% \mathrm{Cl}$ : 0.088 to $1.394 ; p=0.026$ ) during the study period.

The most important factors associated with ADL domain were baseline $\mathrm{BI}(95 \% \mathrm{Cl}: 0.325$ to $0.738 ; \mathrm{p}<$ $0.001)$ and MMSE scores ( $95 \% \mathrm{Cl}: 0,004$ to $0.787 ; \mathrm{p}=0.047)$. Increase of $\mathrm{BI}(95 \% \mathrm{Cl}: 0.752$ to $1.091 ; \mathrm{p}<$ 0.001) was associated with significant increase of $A D L$ and increase of $m R S$ (95\% Cl: -13.290 to $-6.905 ; p$ $<0.001$ ) was associated with significant decrease of ADL domain.

The possible predictors of the mobility domain were baseline mRS ( $95 \% \mathrm{Cl}: 4.791$ to $17.343 ; p=0.001$ ). Increase of $\mathrm{BI}(95 \% \mathrm{Cl}: 0.818$ to $1.153 ; \mathrm{p}<0.001)$ and MMSE scores ( $95 \% \mathrm{Cl}: 0.413$ to $1.931 ; \mathrm{p}=0.003)$, were significantly positive associated with increase of mobility domain. But, increase of $\mathrm{mRS}(95 \% \mathrm{Cl}$ : -9.424 to $-3.017 ; p<0.001)$ and NIHSS scores $(95 \%$ Cl: -2.188 to $-0.894 ; p<0.001)$ were significantly associated with decreased of mobility.

Baseline value of $\mathrm{mRS}(95 \% \mathrm{Cl}:-24.580$ to $-18.262 ; \mathrm{p}<0.001)$ was important predictor for physical functioning and increase of $\mathrm{mRS}(95 \% \mathrm{Cl}$ - -25.125 to $-12.628 ; p<0.001)$ was associated with significantly 
decreased of physical functioning.

The most important predictors for improvement of hand function were baseline mRS and NIHSS scores and increase of the mRS during the study.

The most important factor predicting decreased of participation role was increase of $\mathrm{mRS}(95 \% \mathrm{Cl}$ : -35.012 to $-24.133 ; p<0.001)$.

\section{Discussion}

We found that stroke survivors were significantly disabled with decreased of all eight domains of HRQOL when they were admitted to the inpatient rehabilitation. Hand function, physical functioning, mobility and ADL domains were the most affected.

According to the presented results, baseline mRS and NIHSS scores were significantly negatively correlated with HRQOL. Decreasing of $\mathrm{mRS}$ and NIHSS scores during the six months were positively correlated with the recovery of all affected domains, especially with the recovery of physical functioning, hand function and participation role.

Recovery of physical function in our study had great impact on the improvement of all other domains of HRQOL such as emotion, communication, ADL and participation role. Numminen et al. [27] found that despite of good physical recovery stroke survivors reported some impairments in HRQOL six months after the stroke.

In our study improvement of hand function significantly influenced on the overall HRQOL of survivors. In the study of Carod-Artal et al. [19], NIHSS, BI and mRS were the main predictors for the recovery of strength domain, the MMSE was the main predictor for the memory and communication domains, $\mathrm{BI}$ and mRS were predictors for the ADL and hand function domains. Our results are partially in agreement with these findings.

In our study, factors that significantly correlated with lower HRQOL scores were greater stroke severity, physical disability and hand dysfunction. Our findings are in agreement with the findings of Numminen et al. [27], Alguren et al. [28], Pinkey et al. [29] and Yeoh et al. [30].

Stroke severity, dependence in $A D L$, degree of handicap, and length of hospitalization were important factors associated with worsen quality of life in stroke survivors after thromolitic therapy [27]. Findings of Alguren et al. [28] showed the predictability of baseline NIHSS score for HRQOL in the chronic phase. Greater stroke severity measured by NIHSS at admission was predictor of worsen HRQOL [29]. Our results are in agreement with results of these studies.

Study of Rønning and Stavem [33] showed that neither age, sex, comorbidity, nor baseline disability was an important determinant of change in HRQOL from one to six months following acute stroke. Only 
baseline scores in SF-36 questionnaire were associated with changes in HRQOL from one month to six months after stroke.

In our study age was not associated with any SIS domain six months after discharge from the inpatient rehabilitation. One more study didn't find any association between age and sex and HRQOL in stroke survivors [21]. Pinkey et al. [29] found insignificant association between older age and worsen HRQOL in stroke survivors. Gurcay et al. [16] found that age and functional status were the most important independent factors which were associated with HRQOL.

We found that female sex with stroke in right hemisphere and increase of BI scores during the six months was predictor for improvement of memory domain. In our study right hemisphere stroke predicted lower emotion domain in survivors six months after discharged from inpatient rehabilitation. Chen et al. [21] showed similar findings. Yeoh et al. [30] showed that stroke side only had impact on the motoric functions, but not on the emotional domain of HRQOL.

Different results presented Hopman et al. [34]. They found that the left hemisphere stroke predicted worse emotional functioning even six months of follow-up. Study of de Haan et al. [35] showed that locations of stroke and stroke types did not affect emotional domain of quality of life.

In our study communication domain was significantly negative correlated with stroke in the brainstem. The brainstem stroke can result in loss of motor function and with appearance of other symptoms such as ataxia, double vision, vertigo, and dizziness, difficulty swallowing, speech deficits, numbness, and even paralysis of one side of the body or both.

Niemi et al. [31] found that patients with either a right or left hemisphere stroke had more frequently evidenced deterioration of quality of life than patients with no brainstem lesions. One study showed worse quality of life in patients with left hemispheric stroke [32].

Survivors in our study with ischaemic stroke had significantly higher scores in memory, communication and hand domains compared with those with hemorrhage. Chen et al. [21] showed similar results.

Recovery of hand function wasn't significant until six months after the inpatient rehabilitation and recovery of this domain significantly increases the overall $H R Q O L$ of stroke survivors in our study. Morris et al. found that impairment of hand function and ADL independence predicted perceived physical activity [17]. According to the results of Nichols-Larsenet al. [36] worsen HRQOL in the physical domain was associated with age, more comorbidities and reduced hand function.

\section{Conclusion}

According to presented results, major factors in predicting the improvement of strength, physical functioning, mobility, hand function, $A D L$ and participation role were increase of $B I$ and decrease of mRS and NIHSS scores. Female sex, stroke in right hemisphere and increase of $\mathrm{BI}$ and MMSE scores predicted 
better memory. Baseline mRS and NIHSS scores were predictors for improvement of hand function and increase of the mRS predicted decrease of hand function and participation role.

\section{Abbreviations}

WHO-The World Health Organization

USA-the United States of America

HRQOL-Health-Related Quality of Life

Cl-confidence interval

BI- Barthel Index

mRS- modified Rankin Scale

MMSE- Mini-Mental State Examination;

NIHSS- National Institutes of Health Stroke Scale

SIS-Stroke Impact Scale

SF-36-Short Form health survey questionnaire

ADL-activity of daily living

TIA-transistent ischaemic attack

\section{Declarations}

Ethics approval and consent to participate: The study was approved by the Ethics Committee of the Medical Faculty in Niš, Serbia, number of Decision: 01-206-8. Also, permission to conduct this study gave the Ethics Committee of the Clinical Center of Niš, Serbia, number of Decision: 2280/12.

We require from all participants the written consent to participate in the study. It was one of condition to involve them to the study.

Consent for publication: "Not applicable"

Availability of data and materials: The datasets generated and analysed during the current study are not publicly available due [conteint data from medical histories of participants] but are available from the corresponding author on reasonable request.

Competing interests: The authors declare that they have no competing interests. 
Funding: There isn't any funding.

Acknowledgement: We are thankful to the Clinic for rehabilitation and physical medicine, of the Clinical Center Niš, Serbia, because it gave us the permission to do the study.

\section{Author contributions:}

1. RN-create the study design, distributed the questionnaires to the participants formed data base for statistical analysis, wrote the manuscript, act as corresponding author

2. MM-helped in distribution of questionnaires to the participants, collected data from the survivors, did the clinical examination

3. BD-did all statistical analysis

4. KB- substantively revised the manuscript

5. LK- approved the submitted version

All authors have read and approved the final manuscript.

\section{References}

1. Donkor ES. Stroke in the $21^{\text {st }}$ Century: A Snapshot of the Burden, Epidemiology, and Quality of Life. Stroke Research and Treatment. 2018. Available at: https://doi.org/10.1155/2018/3238165

2. World Health Organization. Stroke-1989. Recommendations on stroke prevention, diagnosis, and therapy. Report of the WHO Task Force on stroke and other cerebrovascular disorders. Stroke. 1989;20:1407-31.

3. Cramer SC, Wolf SL, Adams HP, Chen D, Dromerick AW, Dunning K et al. Stroke Recovery and Rehabilitation Research: Issues, Opportunities, and the National Institutes of Health StrokeNet. Stroke. 2017 Mar;48(3): 813-19. doi: 10.1161/STROKEAHA.116.015501. Epub 2017 Feb 7.

4. Feigin, VL, Roth, GA, Naghavi, M. Global burden of stroke and risk factors in 188 countries, during 1990-2013: A systematic analysis for the Global Burden of Disease Study 2013. Lancet Neurol. 2016; 15(9): 913-24.

5. Krishnamurthi VR, Feigin LV, Forouzanfar HM, Mensah AG, Connor M, Bennett AD et al. Global and regional burden of first-ever ischaemic and haemorrhagic stroke during 1990-2010: findings from the Global Burden of Disease Study 2010. Lancet Glob Health. 2013; 1(5): e259-e281. doi:10.1016/S2214-109X(13)70089-5.

6. Johnson W, Onuma O, Owolabi M, Sachdev S. Stroke: a global response is needed. Bulletin of the World Health Organization2016; 94:634-634A. doi: http://dx.doi.org/10.2471/BLT.16.181636

7. Lackland TD, Roccella JE, Deutsch A, Fornage M, George GM, Howard G et al. Factors Influencing the Decline in Stroke Mortality: A Statement from the American Heart Association/American Stroke Association. Stroke. 2014; 45(1):315-53. 
8. Towfighi A, Saver JL. Stroke Declines From Third to Fourth Leading Cause of Death in the United States Historical Perspective and Challenges Ahead. Stroke. 2011;42:2351-2355.

9. GBD 2016 Disease and Injury Incidence and Prevalence Collaborators: Global, regional, and national incidence, prevalence, and years lived with disability for 328 diseases and injuries for 195 countries, 1990-2016:a systematic analysis for the Global Burden of Disease Study 2016. Lancet 2017; 390: 1211-259.

10. GBD 2016. Causes of Death Collaborators: Global, regional, and national age-sex specific mortality for 264 causes of death, 1980-2016: a systematic analysis for the Global Burden of Disease Study Lancet 2017; 390: 1151-1210.

11. Tang EY, Amiesimaka O, Harrison SL, Green E, Price C, Robinson Let al. Longitudinal Effect of Stroke on Cognition: A Systematic Review. J Am Heart Assoc2018: 15;7(2). doi: 10.1161/JAHA.117.006443.

12. Mijajlović DM, Pavlović A, Brainin M, Heiss WD, Quinn JT, Ihle-Hansen BH et al. Post-stroke dementia-a comprehensive review. BMC Medicine 2017;15:1 doi: 10.1186/s12916-017-0779-7

13. Kongsawasdi S, Klaphajone J, Wivatvongvana P, Wan Watcharasaksilp K. Prognostic Factors of Functional Outcome Assessed by Using the Modified Rankin Scale in Subacute Ischemic Stroke. J Clin. Med Research 2019:11(5):375-82.

14. 14. Salter KL, Moses MB, Foley NC, Teasell RW. Health-related quality of life after stroke: what are we measuring? Int J Rehabil Res. 2008 Jun;31(2):111-7. doi: 10.1097/MRR.0b013e3282fc0f33.

15. Chan MA Chia-Yeh. Determinants of the Health-related Quality of Life for Stroke Survivors. J of Stroke and Cerebrovascular Diseases. 2015; 24(3): 655-62.

16. Gurcay E, Bal A, Cakci A. Health-related quality of life in first-ever stroke patients. Ann Saudi Med. 2009;29:36-40.

17. Morris JH, van Wijck F, Joice S, Donaghy M. Predicting health related quality of life 6 months after stroke: the role of anxiety and upper limb dysfunction. Disabil Rehabil. 2013;35:291 - 99.

18. Yeoh YS, Koh GC-H, Tan CS, Tu TM, Singh R, Chang HM et al. Health-related quality of life loss associated with first-time stroke. PLoS ONE. 2019; 14:1 Available at: https://doi.org/10.1371/journal.pone.0211493

19. Carod-Artal J, Egido JA, Gonzalez J, de Selijaz V. Quality of life among stroke survivors evaluated 1 year after stroke. Stroke. 2000; 31:2995-3000.

20. Hamza AM, Al-Sadat N, Loh SY, Jahan Predictors of Post-stroke Health-Related Quality of Life in Nigerian Stroke Survivors: A 1-Year Follow-Up Study. Biomed Res Int. 2014; 2014: 350281. doi: 10.1155/2014/350281

21. Chien-Min C, Chih-Chien T, Chia-Ying C, Chia-Ling C, Wu Katie PH, Hsieh-Ching C. Potential predictors for health-related quality of life in stroke patients undergoing inpatient rehabilitation. Health and Quality of Life Outcomes. 2015; 13:118; doi: 10.1186/s12955-015-0314-5

22. Granger CV, Devis LS, Peters MC, Sherwood CC, Barrett JE. Stroke rehabilitation: analysis of repeated Barthel Index measures. Arch Phys Med Rehabil.1979;60:14-17. 
23. Rankin J. Cerebral vascular accidents in patients over the age of 60. li. Prognosis. Scott Med J. 1957;2:200-15.

24. Folstein MF, Folstein SE, McHugh PR. "Mini-mental state". A practical method for grading the cognitive state of patients for the clinician. J Psychiatr Res. 1975;12(3):189-98.

25. Wityk RJ, Pessin MS, Kaplan RF, Caplan LR. Serial assessment of acute stroke using the nih stroke scale. Stroke. 1994;25:362-5.

26. Brott T, Adams HP, Olinger CP, Marler JR, Barsan WG, Biller J, et al. Measurements of acute cerebral infarction: a clinical examination scale. Stroke. 1989;20: 864-70.

27. Numminen S, Kopijakko-Huujke AM, Parkkila AK; Kulkus T, Nuimmenen HJ et al. Factors influencing Quality of Life Six Months after a First-Ever Ischamic Stroke: Focus on Thrombolyzed Patients. Karger AG. 2016. doi: 1021-7762/16/0086539-50/0

28. Alguren B, Fridlund B, Cieza A, Sunnerhagen KS, Christensson L. Factors associated with healthrelated quality of life after stroke: a 1-year prospective cohort study. Neurorehabil Neural Repair. 2012;26:266-74. doi: 10.1177/1545968311414204.

29. Pinkney AJ, Gayle F, Mitchell-Fearon K, Mullings J. Health-Related Quality of Life in Stroke Survivors at the University Hospital of the West Indies. Journal of Neurology Reseach. 2017;7 (3):46-58.

30. Yeoh, YS, Koh, GC, Tan, CS et al.Can acute clinical outcomes predict health-related quality of life after stroke: a one-year prospective study of stroke survivors. Health Qual Life Outcomes. 2018; 16: 221 doi:10.1186/s12955-018-1043-3

31. Niemi M, Laaksonen R, Kotila M, Waltimo O. Quality of life 4 years after stroke. Stroke.1988; 19:1101107.

32. Ramos-LimaMJM, de Carvalho Brasileiro I, de Lima LT, Braga-Neto Quality of life after stroke: impact of clinical and sociodemographic factors. Clinics (Sao Paulo). 2018; 73: e418. Published online 2018 Sep 24. doi: 10.6061/clinics/2017/e418

33. Rønning OM, Stavem K. Determinants of change in quality of life from 1 to 6 months following acute stroke. Cerebrovasc Dis. 2008;25:67-73.

34. Hopman MW, Verner J. Quality of Life During and After Inpatient Stroke Rehabilitation. Stroke 2003;34:801-805.

35. de Haan RJ, Limburg M, Van der Meulen JH, Jacobs HM, Aaronson NK. Quality of life after stroke. Impact of stroke type and lesion location. Stroke.1995;26:402-08.

36. Nichols-Larsen SD, Clark, Zeringue A, Greenspan A, Sarah. Factors Influencing Stroke Survivors' Quality of Life During Subacute Recovery. Stroke.2005;36(7):1480-4. 